\title{
Central Nervous System Infectious Disorder
}

National Cancer Institute

\section{Source}

National Cancer Institute. Central Nervous System Infectious Disorder. NCI Thesaurus.

Code C27582.

An infectious process that affects the brain and/or spinal cord. Representative examples include encephalitis, poliomyelitis, arachnoiditis, and mening itis. 